\title{
Performance And Emission Characteristics Of C.I. Engine Fuelled With Diesel-Biodiesel Blends
}

\author{
Jalpit B. Prajapati ${ }^{1}$, Parth R. Panchal ${ }^{2}$, Tushar M. Patel ${ }^{3}$ \\ ${ }^{\prime}$ (Mechanical Engg. Dept., Gandhinagar Institute of Technology,India) \\ 2 (Mechanical Engg. Dept., Gandhinagar Institute of Technology,India) \\ ${ }^{3}$ (Mechanical Engg. Dept.,L.D.R.P., Gandhinagar, India)
}

\begin{abstract}
Environmental concern and availability of petroleum fuels have caused interest in the search for alternative fuels for internal combustion engine. Many alternate fuels are tried by various researches. Based on literature review it is found that for diesel engine Bio Diesel is most promising fuel. In this project works prospects and opportunities of utilizing biodiesel and increasing biodiesel-diesel blend ratio as fuel in diesel engine is going to be studied by fixed compression ratio. Also based on experimentation an optimum blend and engine parameters are to be suggested for obtaining better performance and emission control. Biodiesel is present a functioning as alternative fuels to diesel fuel. The properties of these can be compared favorably with the characteristics required for internal combustion engine fuels specially diesel engine. Experiments will performed for fixed compression ratio i.e. 18 using biodiesel diesel blends i.e. BO, B10, B20, B30, with load variation from no load to full load and compared with base cases i.e. engine using diesel as a fuel. The parameters which will study in performance brake power, brake specific fuel consumption and brake thermal efficiency, In emission carbon monoxide, unburnt hydrocarbons, nitrogen oxide. As per the literature survey B20 (20\%biodiesel and 80\% diesel) is best in performance compare to other blends. But NOx formation is also little higher in $B 20$.
\end{abstract}

Keywords : Palm biodiesel, Performance, Emission, Diesel-Biodiesel blend

\section{Introduction}

Diesel engine dates back to 1892 when Rudolf Diesel invented the compression-ignition engine [1]. It is widely used in power generation, transportation and agricultural machinery sectors. As of today, diesel engine is playing a more and more dominant role due to its superior thermal efficiency and fuel economy. However, its exhaust emissions have become the major concerns due to their environmental impacts. As such, emission regulations have been made more and more stringent during the past few years, and this has posed serious challenges to the researchers and engine manufacturers. As advance technologies becoming available, researchers are looking into new strategies such as common rail fuel injection, multiple injections and low temperature combustions to reduce the harmful emissions and increase the engine efficiency. However, the rising oil prices and concerns on the depletion of fossil fuel reserves have forced researchers to not only look into engine optimization, but also find alternative resources to tackle the energy crisis. Biodiesel has gained a growing interest as one of the most promising solutions. Its primary advantages are biodegradable, renewable, carbon neutral and do not produce hazardous toxic gases [2]. Among this, biodiesels have received increasing attention as an alternative fuel because they can be employed in diesel engines without needing modification. Furthermore, fuel properties of biodiesel are almost similar to diesel fuel.

\subsection{Benefits of biodiesel as an alternate fuel}

Biodiesel is nontoxic, degrades four rime faster than diesel[1]. Blending of bio-diesel with diesel fuel increases engine efficiency[1]. 90\% reduction in cancer risks, according to Ames mutagenicity tests [1]. Biodiesel does not produce greenhouse effects, because the balance between the $\mathrm{CO} 2$ emissions and $\mathrm{CO} 2$ absorbed by the plants producing vegetable oil is equal[1]. The high flash point makes the storage safer [1].

\subsection{Challenges of biodiesel as an alternative fuel}

Slight decrease in fuel economy on energy basics (about 10\% for pure bio-diesel)[3]. Density is more than diesel fuel in cold weather, but may need to use blends in sub-freezing conditions[3]. More expensive due to less production of vegetable oil[3].

\subsection{Process and Types of biodiesel}

Vegetable oil is converted into biodiesel through a chemical process that transesterification and produces methyl ester or ethyl ester. Palm seed oil, Cotton seed oil, Rape seed oil, Soybean oil, Sunflower oil, Olive oil, Karanji oil, Vegetable oil, Jatropha etc. 


\subsection{Motivation}

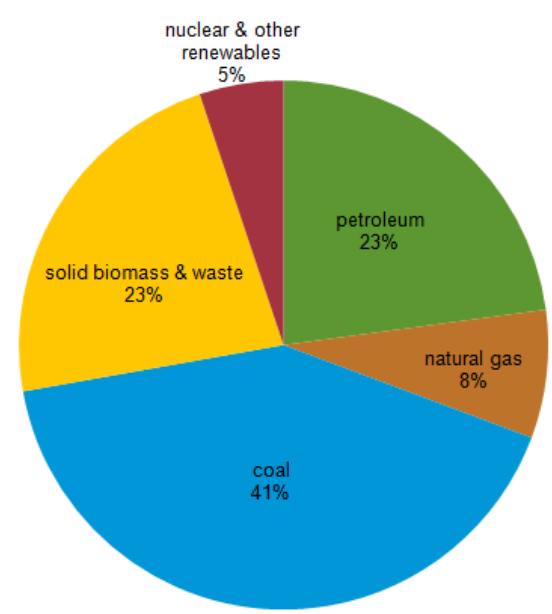

Fig. 1. Total energy consumption in India

After the United States, China and Russia, India is the fourth largest energy consumer in the world. India's economy grew at an annual rate of around 7 percent and proved relatively resilient to the global financial crisis in the world. India's policy of energy above all focuses on securing energy sources to meet the needs of its growing economy. Primary energy consumption is more than doubled. India's per capita energy consumption remains lower than developed countries. The government may not be able to deliver secure supplies because of fuel subsidies, inconsistent energy sector reform and increasing import dependency. Some parts of the energy sector, such as coal production, remain relatively closed to private and foreign investment. Despite having large coal reserves and a healthy growth in natural gas production over the past two decades, India remains very dependent on imported crude oil. India's largest energy source is coal, followed by petroleum and traditional biomass. India's population increasing and moved to cities, and urban households have shifted away from traditional biomass to other energy sources. The industrial sector is the largest energy consumer, 40 percent of India's total primary energy demand. The power sector is the fastest growing area of energy demand, increasing 23 percent to 38 percent of total energy consumption.

\subsection{Objective of the study}

The aim of the experimentation is to check feasibility of biodiesel in C.I. engine fuelled with dieselbiodiesel blends as more biodiesel as possible. The experimental work under this project consists of two parts, Generation of base line performance data from the C.I engine fuelled by diesel, Compare different Dieselbiodiesel blend data with base line data. Optimize the best blend out of given different blends.

\section{Literature review}

W.M.Yang et al. studied that the variation of brake power with engine speed at full load conditions for different tested fuels. It can be seen that the maximum output power at full load conditions are nearly the same for B10 and diesel fuel, and a slight increase in BP is found for B10, indicating an improved combustion with the addition of biodiesel. However, when the biodiesel blend ratio is increased to $50 \%$ or $100 \%$, there is an obvious drop in BP at all engine speeds. The reduction in BP at $3600 \mathrm{rpm}$ is observed to be $5.6 \%$ and $9.7 \%$ for $\mathrm{B} 50$ and $\mathrm{B} 100$ respectively. This is mainly due to the reduction in the lower heating value of biodiesel as explained by Buyukkaya [3] and S. Jindal [4]. The BSFC of different tested fuels at 25\% load. The BSFC of B10 is almost the same as that of diesel fuel at $1200 \mathrm{rpm}$ and $2400 \mathrm{rpm}$, but lowered by $9.5 \%$ at $3600 \mathrm{rpm}$. Labeckas and Slavinskas [5] also claimed that there was a 1.5\% reduction in the BSFC of B10 (rapeseed methyl ester was used as the biodiesel) at rated engine speed under full load condition. They also explained that the slight decrease in BSFC for B10 was due to the fuel borne oxygen. With further increase in the oxygen content for B50 and B100, the BSFC increases significantly ( $42 \%$ and $34.4 \%$ for $800 \mathrm{rpm}$ and $1200 \mathrm{rpm}$, respectively). This is mainly attributed to the decrease in the lower heating value of biodiesel as suggested by most of the researchers $[6,7,8]$. Another reason may due to the high viscosity of biodiesel. When the engine is operating at low speed and partial load conditions, the Fuel/Air equivalence ratios of all tested fuels are already very low such that the oxygenated nature of biodiesel is not an advantage anymore. However, the higher kinematic viscosity of biodiesel predominates the fuel atomization and mixing with air, resulting in a poorer combustion process and reduced thermal efficiency. The brake thermal efficiency of the engine fueled by Diesel, B10, B50 and B100 at $100 \%$ load. At full load condition, the fuel injection pressure can reach as high as 1400 bars such that the viscosity effect is negligible, and the fuel borne oxygen in B100 enables a more complete combustion and hence higher thermal efficiency. The largest BTE is found to be at $2400 \mathrm{rpm}$ under full load conditions and the BTE values for 
Diesel and B100 are $36.3 \%$ and $38.1 \%$, respectively. The variation of CO emission at $25 \%$ load. The CO emission increases significantly as the biodiesel blend ratio increases especially at low engine speed. As explained earlier, this may attribute to the higher viscosity of biodiesel which predominates the combustion process when the engine is operating at low speed and partial load conditions. Also compares the $\mathrm{CO}$ emission of diesel and B100 at all engine operating conditions. It can be seen that the with the use of our Euro IV common rail fuel injection diesel engine, the CO emission drops to extremely low levels at $50 \%$ and $100 \%$ loads. However, different trend is observed at partial load $(25 \% \mathrm{load})$ condition where limited studies have been reported. The hydro-carbon emissions of all tested fuels are found to be very low at all engine operating conditions. The variation of $\mathrm{HC}$ emissions of the engine fuelled by diesel and B100 at the 12 operating conditions considered in this study. It can be seen that under all the engine operating conditions except those at $800 \mathrm{rpm}$ and partial load conditions (25\% load), the HC emission is lower for B100 as compared to those of diesel, implying that the use of biodiesel generally results in lower $\mathrm{HC}$ emissions due to its cleaner combustion. It also shows that the engine idle speed and partial load condition have a vital influence on the behavior of engine combustion and exhaust emissions. The nitrogen oxides emissions are very sensitive to the combustion temperature which generally increases with the increase of engine speed and engine load. The variation of NOx emissions with the engine speed at $100 \%$ load. The correlation between biodiesel blend ratio and the NOx emissions are very random at different engine speeds and loads. However, it is worth noting that under all the engine operating conditions except those cases at low engine speed and high engine load (800 rpm and $50 \%$ load, $800 \mathrm{rpm}$ and $100 \%$ load, $1200 \mathrm{rpm}$ and $100 \%$ load), the NOx emissions produced by B100 are lower compared to diesel. So it indicates that the engine idle speed of $800 \mathrm{rpm}$ may also have a significant effect on the engine combustion and emission formation processes. Many researchers have studied the impact of biodiesel on the NOx emissions, and according to Xue et al. [9], about $65.2 \%$ believed that the NOx emissions increase with the increase of biodiesel blend ratio. For example, Luján et al. [10] did an experimental study using a HSDI four cylinder diesel engine on the effect of biodiesel on engine performance and emissions, and it was observed the NOx emissions increased by $20.6 \%, 25.9 \%$ and $44.8 \%$ for B30, B50 and B100 respectively. However, there are still some researchers who have reported reduced NOx emissions or no regularity observed with the increase of biodiesel blend ratio.

K.J.Chua et al. studied that BSFC can be thought of as power specific fuel consumption which quantifies the fuel efficiency. The BSFC of the test engine while running with diesel, B10, B20, B50 and B100 fuels at full load conditions. It indicates that the BSFC generally increases with the biodiesel blend ratio, and the average increase in BSFC over all engine speeds are 2.1\%, 1.5\%, 3.5\% and 9.6\% for B10, B20, B50 and B100 respectively. The experimental results show that no general correlation can be confirmed between the BTE and biodiesel blend ratio, however, it can be observed that the BTE values of B100 are consistently lower compared to diesel under lower load conditions and the percentage reduction increases as the engine load decreases. At higher load conditions, B100 even has a better BTE than diesel. the variation of heat release rate of the tested fuels at $10 \%, 50 \%$ and $100 \%$ loads. It can be seen that no general correlation can be drawn between the biodiesel blend ratio and the heat release rate, however, it is worthy to note that the heat release rate of B100 is consistently lower than diesel at all engine loads. Again this can attribute to the lower calorific value of biodiesel as compared to diesel. Furthermore, with the start of combustion (SOC) close to each other, the end of combustion (EOC) occurs earlier for B100 as compared to diesel at all engine loads, indicating a shorter combustion duration for biodiesel. To evaluate the effect of engine loads on the combustion characteristics, engine cylinder pressures are compared under different engine loads and at a medium engine speed of $2400 \mathrm{rpm}$. The variations of cylinder pressure for the tested fuels at 10\%, 50\% and $100 \%$ loads respectively. It can be seen that with the use of biodiesel, the peak cylinder pressure slightly decreases as compared to diesel, leaving B100 to be the lowest. This again may due to the lower calorific value of biodiesel as compared to diesel. The exhaust $\mathrm{CO}$ emissions are evaluated at low, medium and high loads. It is observed that the trends of $\mathrm{CO}$ emission with respect to engine speed and biodiesel blend ratio are significantly affected by the engine loads. The variation of CO emissions with engine speed for different fuels at $10 \%$ load. The CO emission generally decreases with the increasing engine speed and decreasing biodiesel blend ratio. The same trend is also observed at $25 \%$ load. This is postulated here that at lower load combustion conditions, the fuel air ratio becomes too lean for a complete combustion especially at lower engine speeds. When the engine is running on biodiesel, the extra oxygen atoms contained in the biodiesel further reduces the fuel air ratio, causing the flame temperature to drop very fast, resulting in a higher $\mathrm{CO}$ emission. Furthermore, as mentioned earlier, the viscosity effect of B100 plays a significant role on the combustion process during partial load conditions, increasing the tendency for an incomplete combustion. With the use of our Euro IV common-rail fuel injection diesel engine, the HC emissions of tested fuels are observed to be very low at all engine load conditions. The variation of $\mathrm{HC}$ emissions of diesel, biodiesel and their blend fuels with respect to engine speed at full load conditions. Even though there is no linear correlation can be drawn between the biodiesel blend ratio and $\mathrm{HC}$ emissions, generally, one still can see that the use of biodiesel improves the combustion process and reduces the $\mathrm{HC}$ emissions. The same trend is also 
observed at other engine load conditions, and there is no detrimental effect found on the $\mathrm{HC}$ emissions with the use of biodiesel. The NOx emission is very sensitive to the engine combustion temperature which increases with the increasing engine speed and load. It is generally agreed that the higher the cylinder temperature, the higher the NOx emissions. However to monitor the cylinder temperature would be highly impossible, and some researchers have been trying to find the correlation between engine exhaust temperature and the NOx emissions since the exhaust temperature is a good indicator of engine combustion temperature. For example, Al-Shemmeri and Oberweis found that the NOx increase was directly proportionally to the engine exhaust temperature [9]. However, even though our experimental results show that the exhaust temperature decreases with the increasing biodiesel blend ratio, it can be seen that the correlations between the NOx emission and biodiesel blend ratio at $10 \%, 50 \%$ and $100 \%$ loads are very random. Nevertheless, it is still worth noticing that the NOx emission increases significantly with the increasing engine load for all the tested fuels.

\section{Experimental setup and specifications} Table 1

Engine specifications

\begin{tabular}{lc}
\hline No. of cylinder & 1 \\
No. of strokes & 4 \\
Cylinder diameter & $87.5 \mathrm{~mm}$ \\
Stroke length & $110 \mathrm{~mm}$ \\
Connecting rod length & $234 \mathrm{~mm}$ \\
Orifice diameter & $20 \mathrm{~mm}$ \\
Dynamometer arm length & $185 \mathrm{~mm}$ \\
Rated power & $3.5 \mathrm{~kW}$ \\
\hline
\end{tabular}

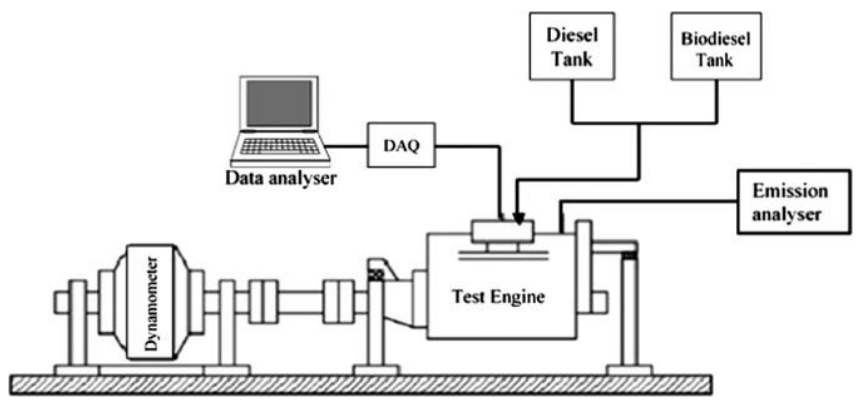

Fig. 2. Schematic diagram of experimental setup

\subsection{Experimental procedure}

To carry out tests using biodiesel blends, the engine was run with diesel until a steady operating condition was achieved. Then the fuel was changed to biodiesel blend. After consumption of sufficient blend fuel, the data acquisition was started to ensure the removal of residual diesel in the fuel line. After each test, the engine was again run with diesel to drain all of the blend out of the fuel line. This procedure was followed for all blends. The test fuels were fossil diesel (B0), 10\% palm oil in diesel (B10), 20\% palm oil in diesel (B20) and $30 \%$ palm oil in diesel (B30). The engine was operated between no load to full load condition at $1500 \mathrm{rpm}$. The performance and emission measurements were triplicated.

\subsection{Characterization of biodiesel from used palm oil}

\section{Results and discussion}

Biodiesel produced from used palm oil was characterized for its fuel properties like density, viscosity, calorific value, flash point, cetane number [10]. These fuel properties were compared with diesel fuel. Flash point was higher than diesel this confirmed the safety of biodiesel storage. Kinematic viscosity and density were higher than diesel this may result in improper spray characteristics. Cetane number was found out using saponification value and iodine value [11]. Cetane index was higher than diesel and it would have positive impact on combustion quality of biodiesel. The fuel properties of biodiesel are shown in table 2 .

\subsection{Brake power output}

The brake power outputs from the engine with different tested fuels are shown in fig. 3 . The brake power increased with increased in load at $1500 \mathrm{rpm}$. The maximum brake power recorded at full load condition. At 100\% load, B30 has better performance than B0. This higher power output could be attributed to a number of causes. The higher density and kinematic viscosity of fuels result in the injection of a larger mass of fuel to the engine for the same fuel volume [12]. Again, the greater the viscosity of the blend, the less the leakage in the fuel pump [13,14]. A higher mass flow compensates for the lower heat energy content of blends [15]. Koçar [16] 
reported higher $\mathrm{CNs}$ of blends. Thus, a higher $\mathrm{CN}$ together with a higher mass flow might have helped to achieve a better power output.

Table 2

Test fuel properties

\begin{tabular}{lll}
\hline Fuel property & Palm oil & Diesel \\
\hline Density at $15^{\circ} \mathrm{C}\left(\mathrm{kg} / \mathrm{m}^{3}\right)$ & 882 & 850 \\
Viscosity at $40^{\circ} \mathrm{C}\left(\mathrm{mm}^{2} / \mathrm{s}\right)$ & 7.01 & 2.60 \\
Calorific value $\mathrm{kJ} / \mathrm{kg}$ & 39891 & 42200 \\
Flash point $\left({ }^{\circ} \mathrm{C}\right)$ & 110 & 68 \\
Cetane number & 77 & 48 \\
Ash content $(\%)$ & $\mathrm{NIL}$ & 0.01 \\
\hline
\end{tabular}

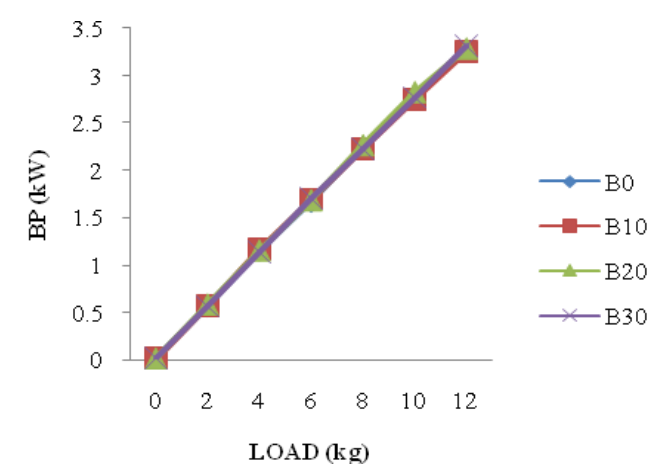

Fig. 3. Brake power vs. load for different blends

\subsection{Brake thermal efficiency}

Fig. 4 represents the variation of brake thermal efficiency of the test fuels with respect to load. Brake thermal efficiency of all test fuels increased as the load increased. This could be explained as the load increases, suction pressure developed will be higher which might have resulted in efficient combustion. The same trend was noted for methyl esters of rubber seed oil and cotton seed oil but on contrary an increase in brake thermal efficiency was noted for ethyl esters of waste vegetable oil, this increase may be due to the enhanced lubricity of the esters $[17,18,19]$.

\subsection{Brake specific fuel consumption}

Fig. 5 represents BSFC of test fuels at different loads. BSFC and brake thermal efficiency are always opposite to each other. BSFC decreased with increased in load. From all blends B30 has better performance as compared to B0. Similar result was noticed for blends with higher content of ethyl esters of waste vegetable oil [18]. Waste cooking oil and rapeseed oil-diesel blends also exhibited similar profile [20,21]. Because of lower calorific value of biodiesel and its blends compared to diesel, more amount of fuel is required to produce the same power output [19].

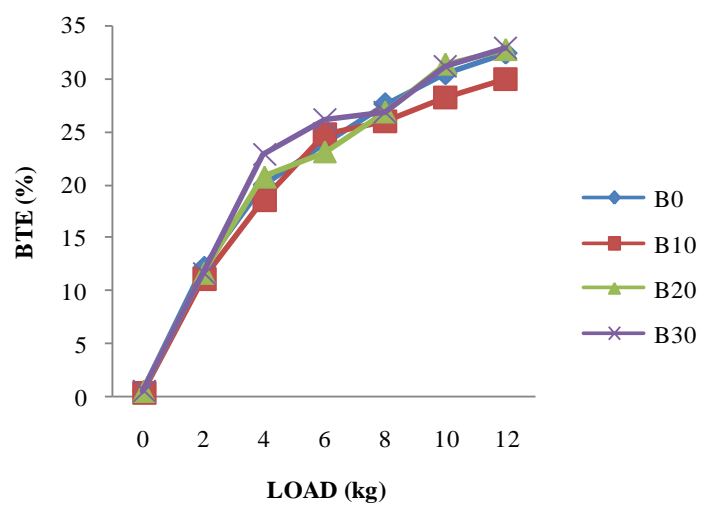

Fig. 4. Brake thermal efficiency vs. load for different blends 


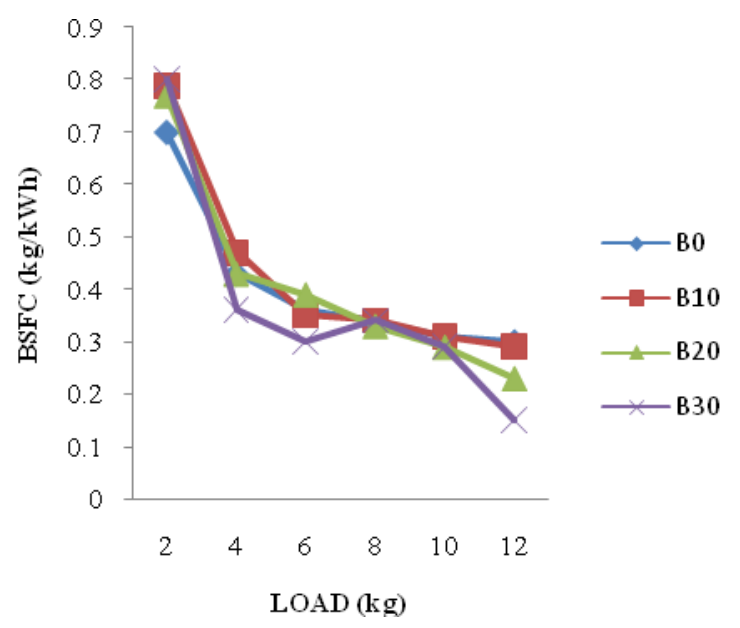

Fig. 5. Brake specific fuel consumption vs. load for different blends

\subsection{Carbon monoxide}

Fig. 6 shows the variation of carbon monoxide emission for test fuels at different loads. $\mathrm{CO}$ is usually formed when there is no sufficient $\mathrm{O}_{2}$ to oxidize the fuel. $\mathrm{CO}$ decreased with increased in loads. From the different blends, B30 has better performance as compared to B0. Lower CO emissions can be attributed to the combined effect of their oxygen content and higher $\mathrm{CN}$ [22]. A higher $\mathrm{CN}$ exhibits a shorter ignition delay and allows a longer combustion duration. Then the oxygen content of biodiesel comes into play, which enhances the combustion process.

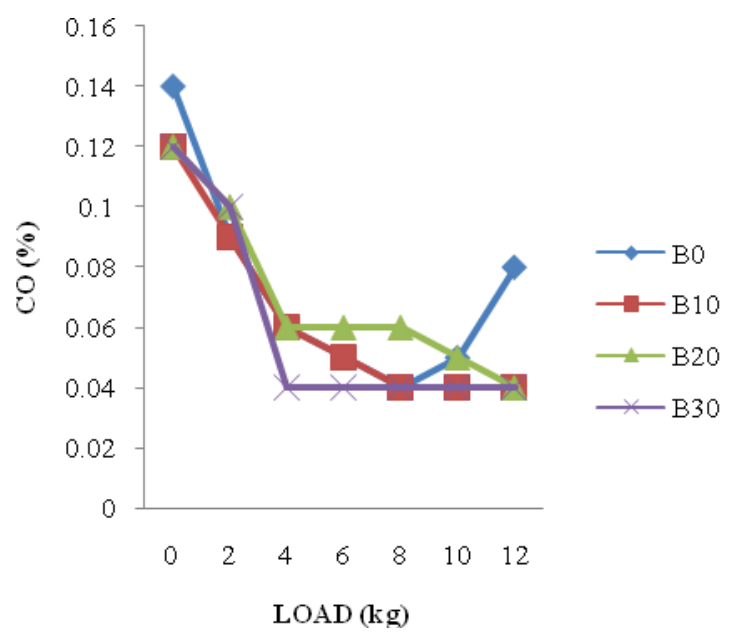

Fig. 6. Carbon monoxide vs. load for different blends

\subsection{Unburnt hydrocarbons}

Fig. 7 shows the variation of hydro carbon emissions with load. The concentration of HC in diesel exhaust varies from few ppm to several thousand ppm depending upon the load on the engine. The hydrocarbons in diesel exhaust are composed of mixture of many individual hydrocarbons in the fuel supplied to the engine as well as partly burned hydrocarbons produced during combustion process [23]. $\mathrm{HC}$ emission is decreased as compared to diesel. The increased gas temperature and higher cetane number of biodiesel and their blends were responsible for this decrease. 


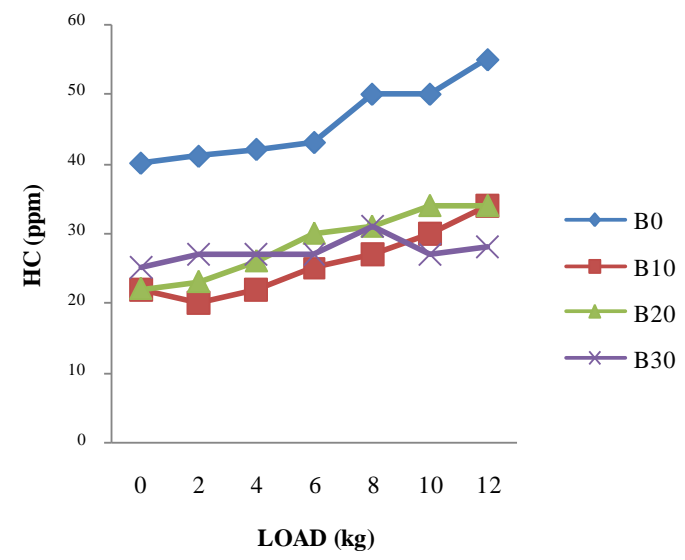

Fig. 7. Unburnt hydrocarbons vs. load for different blends

\subsection{Nitrogen oxide}

Fig. 8 shows the NOx emission profile for the test fuels. As load increased NOx emission also increased. Nox emission of all blends decreased as compared to diesel. B30 is better as compared to other blends.

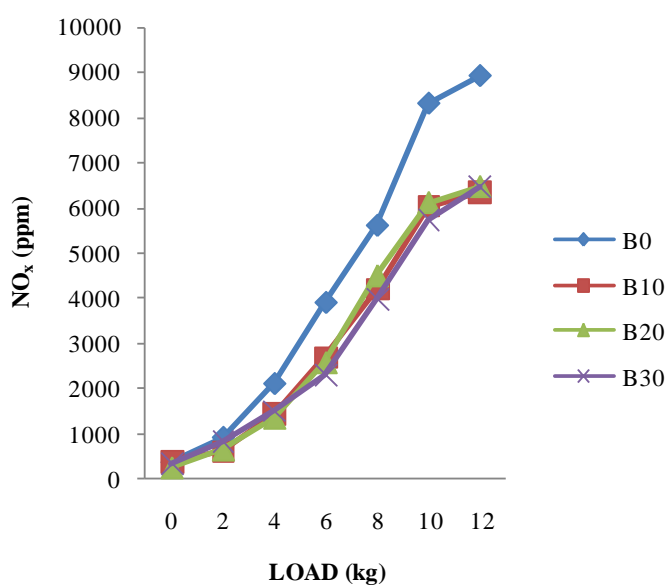

Fig. 8. Nitrogen oxide vs. load for different blends

\section{Conclusion}

Biodiesel produced from palm oil and its blends with diesel showed positive results on performance and emission when tested on a diesel engine. The fuel properties of the biodiesel produced palm oil were within ASTM standards. B30 showed better performance. The results obtained during the test confirmed that biodiesel from palm oil and its blends could be used as a fuel in diesel engine.

\section{References}

[1] Heywood JB. Internal combustion engine fundamentals. In: Duffy A, Morriss JM, editors. New York: McGraw-Hill, Inc.; 1988.

[2] Drapcho C, Nghiem J, Walker T. Biofuels engineering process technology. New York: McGraw-Hill Professional; 2008.

[3]. Ekrem Buyukkaya Eect of biodiesel on a DI diesel engine performance, emission and combustion characteristics, Fuel 89, pp. 3099$310,2010$.

[4]. S. Jindal, B.P. Nandwana, N.S. Rathore, Experimental investigation of the effect of compression ratio and injection pressure in a direct injection diesel engine running on Jatropha, Applied Thermal Engineering 30,pp. 442448, 2010.

[5] Labeckas G, Slavinskas S. The effect of rapeseed oil on direct injection Diesel engine performance and exhaust emissions. Energy Convers Manage 2006;47:1954-67.

[6] Di Y, Cheung CS, Huang ZH. Experimental investigation on regulated and unregulated emissions of a diesel engine fueled with ultra-low sulfur diesel fuel blended with biodiesel from waste cooking oil. Sci Total Environ 2009;407:835-46.

[7] Muralidharan K, Vasudevan D. Performance, emission and combustion characteristics of a variable compression ratio engine using waste cooking oil and diesel blends. Appl Energy 2011;88:3959-68. 
[8] Qi DH, Chen H, Geng LM, Bian YZ. Effect of diethyl ether and ethanol additives on the combustion and emission characteristics of biodiesel-diesel blended fuel engine. Renew Energy 2011;36:1252-8.

[9] Xue JL, Grift TE, Hansen AC. Effect of biodiesel on engine performances and emissions. Renew Sustain Energy Rev 2011;15:1098116.

[10] Knothe Gerhard. Analyzing biodiesel: standards and other methods. JAOCS 2006;83:823e33.

[11] Krisnangkura Kanit. A simple method for estimation of cetane index of vegetable oil methyl esters. JAOCS 1986;63:552e4.

[12] Gumus M, Kasifoglu S. Performance and emission evaluation of a compression ignition engine using apricot seed kernel oil and its blends with diesel fuel. Biomass Bioenergy 2010;34:134-9.

[13] Al-Widyan MI, Tashtoush G, Abu-Qudais Md. Utilization waste vegetable oils as fuel in diesel engines. Fuel Process Technol 2002;76:91-103

[14] Gürü M, Koca A, Can Ö, Çinar C, S_ahin F. Biodiesel production from waste chicken fat based sources and evaluation with Mg based additive in a diesel engine. Renew Energy 2010;35:637-43.

[15] Hazar H, Aydin H. Performance and emission evaluation of a CI engine fuelled with preheated raw rapeseed oil (RRO)-diesel blends. ApEn 2010;87:786-90.

[16] Ileri E, Koçar G. Effects of antioxidant additives on engine performance and emissions of a diesel engine fuelled with canola oil methyl ester-diesel blend. Energy Convers Manage 2013;76:145-54.

[17] Ramadhas AS, Muraleedharan C, Jayaraj S. Performance and emission analysis of a diesel engine fueled with rubber seed oil. Renewable Energy 2005;30:1789e800.

[18] Al-Widyan Mohamad I, Tashtoush Ghassan, Abu-Qudais Moh'd. Utilization of waste vegetable oils as fuel in diesel engines. Fuel Processing Technology 2002;76:91e103.

[19] Nurun Nabi Md, Mustafizur Rahman Md, Shamim Akhter Md. Biodiesel from cotton seed oil and its effects on engine performance and exhaust emissions. Applied Thermal Engineering 2009;29:2265e70.

[20] Hirkude JB, Padalkar AS. Performance and emission analysis of a compression ignition: engine operated on waste fried oil methyl esters. ApEn 2012;90:68-72.

[21] Bari S, Yu CW, Lim TH. Effect of fuel injection timing with waste cooking oil as a fuel in a direct injection diesel engine. Proceedings of the Institution of Mechanical Engineers 2004;218:93e104. 